\title{
Formulation and characterization of transdermal patches for controlled delivery of duloxetine hydrochloride
}

\author{
Amandeep Singh and Alka Bali*
}

\begin{abstract}
Background: Duloxetine hydrochloride is an antidepressant drug also approved for diabetic neuropathy, anxiety disorders, and fibromyalgia requiring repeated administration on chronic basis. The objective of this study was to develop a transdermal drug delivery system for duloxetine hydrochloride as a once daily dosage form.

Methods: Transdermal patches were prepared by solvent evaporation method employing controlled release grades of HPMC in presence or absence of plasticizer PEG-400. FTIR and Differential scanning calorimetry ruled out drug polymer interactions. Standard procedures were used to analyze the prepared films for various physicochemical parameters, drug release (Franz diffusion cell) and skin irritation test.

Results: The formulations were uniform in their physical characteristics with low water vapor absorption, moisture loss and water vapor transmission implying excellent quality and uniformity in patch characteristics. The patches were devoid of hypersensitivity reactions on rat skin. The in-vitro and ex-vivo drug release studies for all the formulations showed that the first dose of the drug was released in 2.0-3.0 $\mathrm{h}$ and nearly complete release (94\%) was achieved in $24 \mathrm{~h}$.

Conclusions: Transdermal patches were successfully prepared for duloxetine hydrochloride and their evaluation suggested excellent quality and uniformity in patch characteristics. This can have potential applications in therapeutic arena offering advantages in terms of reduced dosing frequency, improved patient compliance and bioavailability.
\end{abstract}

Keywords: Duloxetine, Transdermal patches, HPMC, Formulation

\section{Background}

Transdermal drug delivery systems (TDDSs) can be defined as self-contained discrete dosage forms which, when applied to the intact skin, deliver the $\operatorname{drug}(\mathrm{s})$ through the skin portal at a predetermined and reproducible rate into the systemic circulation over a prolonged period of time (Prabhakar et al. 2013; Prausnitz et al. 2004; Gupta et al. 2009). The goal of dosage design for transdermal products is to maximize the flux through the skin into the systemic circulation and simultaneously minimize the retention and metabolism of the drug in the skin. Transdermal delivery provides a leading edge over injectables and oral routes by increasing patient

\footnotetext{
* Correspondence: alka.bali@rediffmail.com

University Institute of Pharmaceutical Sciences, Panjab University, Chandigarh, India
}

compliance and avoiding first pass metabolism, respectively (Selvam et al. 2010).

The first transdermal patch, Transderm-Scop (scopolamine), developed by ALZA Corp (Mountain View, CA, USA) was approved by FDA in 1981 for the treatment of motion sickness and subsequently followed by nitroglycerine patch (Transderm-Nitro) for the management of angina pectoris. In the recent years, TDDS has become one of the most innovative topics for the delivery of drugs. The success of transdermal delivery system in pharmaceutical market is evident from the fact that currently, more than 35 transdermal drug delivery products are approved in the USA for wide variety of pathophysiological conditions including hypertension, angina pectoris, motion sickness, female menopause, and male hypogonadism, and approximately $40 \%$ of drugs are under investigations to validate the feasibility for 
transdermal drug delivery (Barry 2001). The market share for transdermal delivery was $\$ 12.7$ billion in the year 2005, which rose to $\$ 21.5$ billion in the year 2010 and is expected to increase to $\$ 31.5$ billion in the year 2015. In the recent past, several innovative technologies have come up in an attempt to enhance transdermal drug delivery for therapeutic and diagnostic purposes for targeting the delivery of the drugs to specific tissues (Jain and Vyas 1994; Ilana and Joseph 2004; Barry 1987).

The formulation of drugs into a transdermal drug delivery system requires a selection of physicochemical and biological properties (Rani et al. 2011; Izumoto et al. 1992). It is generally accepted that the best drug candidates for passive adhesive transdermal patches must be non-ionic with low molecular weight $(<500 \mathrm{Da})$, having adequate solubility in oil and water $(\log P$ in the range of 1-3), possessing an aqueous solubility $>1 \mathrm{mg} / \mathrm{ml}$, a low melting point (less than $200{ }^{\circ} \mathrm{C}$ ), having $\mathrm{pH}$ of aqueous solution ranging from $5-9$, and having good potency (dose in milligrams per day) (Gordon and Peterson 2003).

Duloxetine $\mathrm{HCl}$ (DLX), N-methyl-3-(naphthalen-1yloxy)-3-(thiophene-2-yl) propan-1-amine hydrochloride (Fig. 1), is a selective serotonin-norepinephrine reuptake inhibitor (SNRI) recommended for the maintenance treatment of major depressive disorder. Originally developed as an antidepressant (Freeman et al. 2013), this drug has now gained approval by the US FDA for several other

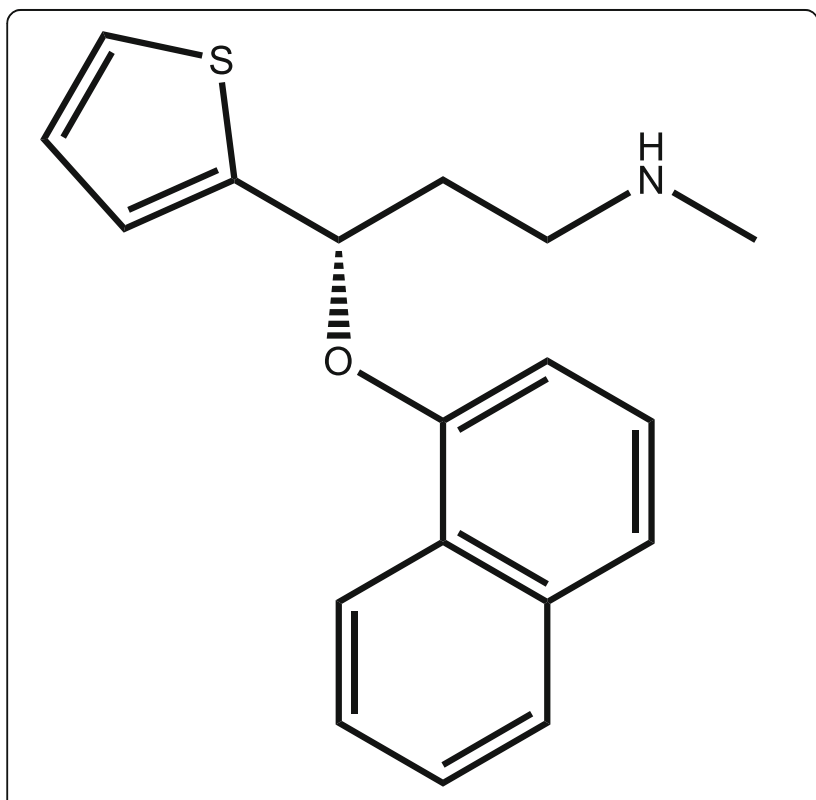

\section{DULOXETINE N-methyl-3-(napthalen-1-yloxy)-3- (thiophene-2-yl) propan-1-amine}

Fig. 1 Chemical structure of duloxetine therapeutic indications including the treatment of neuropathic pain especially diabetic polyneuropathy (first-line treatment) (Goldstein et al. 2005), management of fibromyalgia (Bennett et al. 2012), generalized anxiety disorder (Ball et al. 2013), stress urinary incontinence (SUI) (Mihaylova et al. 2010; Leewen et al. 2008) and most recently, for the treatment of chronic musculoskeletal pain. It has an average half-life of $12 \mathrm{~h}$ with $40-50 \%$ bioavailability. The recommended dose of duloxetine in depression is $40-60 \mathrm{mg} /$ day. The dose for generalized anxiety disorder is $60 \mathrm{mg} /$ day and if necessary, dosage can be increased in increments of not more than $30 \mathrm{mg} /$ day, up to a maximum dose of $120 \mathrm{mg} /$ day [http://www.drugs. com/dosage/duloxetine.html]. This mandates a frequency of administration of duloxetine two to four times per day. The motive of our study was to formulate and characterize the transdermal patches of duloxetine hydrochloride in order to explore the feasibility of this route of administration to provide a once daily formulation for the drug. This would not only reduce its frequency of administration but would also contribute toward increasing its bioavailability and patient compliance. TDDS is considered a good option for drugs intended for chronic behavioral disorders like depression and anxiety as chances of patient non-compliance is very high with other routes of administration.

\section{Methods \\ Materials}

Duloxetine (DLX) pure grade was graciously provided as gift samples by Lupin Pharmaceuticals, Mumbai, India. Hydroxypropyl methylcellulose (HPMC) grades $100 \mathrm{M}$, 4CM, and 15 M CR were generously provided by Panacea Biotech Limited, R\&D Center, Lalru, Punjab, India. All other laboratory chemicals and reagents used in the study were of analytical reagent grade. Double distilled water was used throughout the study. Polyethylene glycol 400 was purchased from S.D. Fine Chem Ltd., Boisar, India. Disodium hydrogen phosphate, potassium dihydrogen phosphate, and sodium hydroxide were purchased from CDH Ltd., New Delhi, India. Ethanol, absolute, was obtained from Changshu Yangyuan Chemical, China. n-Octanol was purchased from E-Merck (India) Ltd., Mumbai, India. Dialysis membrane150 was purchased from Hi Media Laboratories Ltd., Mumbai. All the materials and powders were stored under vacuum at room temperature.

\section{Equipments}

UV spectra were recorded on Perkin Elmer lambda 15 $\mathrm{UV} /$ visible spectrophotometer in the UV/visible range of 190 to $600 \mathrm{~nm}$. Franz diffusion cell assembly was procured from Permegear, Inc., USA. Infrared spectrophotometer FT-IR-8300 was obtained from Perkin Elmer PE 
RX 1 FTIR spectrophotometer. Differential scanning calorimetry (DSC) spectra were obtained using DSC model Q20 V24.2 Build 107 (Universal V4.5A TA Instruments). Research centrifuge was from REMI Equipments, Mumbai, India. $\mathrm{pH}$ meter CyberScan $\mathrm{pH} 510$ was procured from Eutech Instruments, India.

\section{Preformulation studies}

\section{Preparation of phosphate buffered saline $\mathrm{pH} 7.4$}

$0.19 \mathrm{~g}$ of potassium dihydrogen phosphate, $2.38 \mathrm{~g}$ of disodium hydrogen orthophosphate, and $8.0 \mathrm{~g}$ of $\mathrm{NaCl}$ was dissolved in distilled water, and the volume was made up to $1000 \mathrm{ml}$ with distilled water. The $\mathrm{pH}$ of the buffer was adjusted to 7.4.

\section{Quantification of duloxetine hydrochloride}

The content of duloxetine was analyzed by UV spectrophotometric analysis in phosphate buffered saline $\mathrm{pH}$ 7.4. Scanning of the stock solution was carried out in the UV range of 190 to $400 \mathrm{~nm}$. The $\lambda_{\max }$ was obtained at wavelength of $289 \mathrm{~nm}$. Stock solution A $(250 \mu / \mathrm{ml})$ of duloxetine hydrochloride was prepared by dissolving $0.0250 \mathrm{~g}$ of the drug in phosphate buffered saline ( $\mathrm{pH}$ 7.4) to $100 \mathrm{ml}$. Further, serial dilutions ranging from $1 \mu \mathrm{g} / \mathrm{ml}$ to $100 \mu \mathrm{g} / \mathrm{ml}$ of duloxetine were prepared by dilution of stock solutions $\mathrm{A}$ and $\mathrm{B}$ with phosphate buffer ( $\mathrm{pH}$ 7.4). The absorbance values of the dilutions were noted at $\lambda_{\max }$ of DLX, i.e., $289 \mathrm{~nm}$ against phosphate buffered saline ( $\mathrm{pH}$ 7.4) taken as the blank, and calibration curve was plotted.

\section{Physicochemical characterization of duloxetine hydrochloride}

Determination of melting point Small quantity of duloxetine hydrochloride was taken in capillary tube (fused at one end) and placed in melting point apparatus, and the melting temperature was recorded. Three separate measurements were taken for the purpose, and their average value was obtained.

Partition coefficient determination Partition coefficient of duloxetine hydrochloride was determined in octanol-water system (Wells 2002). The two phases were taken in a 1:1 v/v ratio and mutually saturated in a water bath shaker at $37^{\circ} \mathrm{C}$, and the two phases were then separated. Ten milligrams of the drug was added to a mixture of $20 \mathrm{ml}$ of pre-saturated organic phase and $20 \mathrm{ml}$ of pre-saturated water and shaken for $10 \mathrm{~min}$. The flasks were then kept at $37{ }^{\circ} \mathrm{C}$ for $24 \mathrm{~h}$ with intermittent shaking. The mixture was subsequently centrifuged to separate the aqueous and non-aqueous phases. The two phases were separately analyzed for duloxetine spectrophotometrically. The partition coefficient of the drug
" $K_{\mathrm{o} / \mathrm{w}}$ " was then calculated from the ratio of drug concentration in octanol and aqueous phase.

\section{Drug-polymer interaction studies Fourier-transform-infrared spectroscopy}

Fourier-transform-infrared spectroscopy (FTIR) was employed to analyze the pure drug DLX, physical mixture of DLX and HPMC (15 CR, $100 \mathrm{M}$, and $4 \mathrm{M})$, as well as the drug loaded transdermal patches employing $\mathrm{KBr}$ pellets method. All samples were scanned from 400 to $4000 \mathrm{~cm}^{-1}$.

\section{Differential scanning calorimetry}

Possible interactions between the drug and the utilized polymer were analyzed from DSC thermograms of the pure drug duloxetine hydrochloride and the formulation (HPMC + drug) obtained using the DSC model Q20 V24.2 Build 107 (Universal V4.5A TA Instruments). All the samples were sealed in flat-bottomed aluminum pans and heated over a temperature range of 25 to $300{ }^{\circ} \mathrm{C}$ at an increase rate of $5^{\circ} \mathrm{C} / \mathrm{min}$.

\section{Fabrication of transdermal patches}

Transdermal films containing duloxetine hydrochloride were casted on glass slide by solvent evaporation method using different grades (K $15 \mathrm{M} \mathrm{CR}, \mathrm{K} 4 \mathrm{CM}, \mathrm{K}$ $100 \mathrm{M})$ of HPMC in presence and absence of a plasticizer. PEG $400(5 \%)$ was used as a plasticizer in all cases. Table 1 shows the formulae and composition for the different types of formulated patches. Duloxetine hydrochloride $(60 \mathrm{mg})$ was dissolved in water-methanol solvent mixture (7:3). The drug matrix was prepared by dissolving varying concentrations $(1 \%$ and $1.5 \% \mathrm{w} / \mathrm{v})$ of HPMC in the same solvent system. The solution was kept undisturbed for $24 \mathrm{~h}$. Then, with the help of syringe

Table 1 Formulae and composition of formulated transdermal systems of duloxetine $\mathrm{HCl}$

\begin{tabular}{cccccc}
\hline HPMC grade & $\begin{array}{c}\text { Water } \\
\text { content (\%) }\end{array}$ & $\begin{array}{c}\text { Methanol } \\
\text { content (\%) }\end{array}$ & $\begin{array}{c}\text { Percent } \\
\text { PEG 400 }\end{array}$ & $\begin{array}{c}\text { Concentration } \\
\text { of HPMC (\%) }\end{array}$ & $\begin{array}{c}\text { Code } \\
\text { no. }\end{array}$ \\
\hline $15 \mathrm{M} \mathrm{CR}$ & 30 & 70 & 5 & 1.0 & $\mathrm{~A} 1$ \\
$15 \mathrm{M} \mathrm{CR}$ & 30 & 70 & - & 1.0 & $\mathrm{~A} 2$ \\
$15 \mathrm{M} \mathrm{CR}$ & 30 & 70 & 5 & 1.5 & $\mathrm{~A} 3$ \\
$15 \mathrm{M} \mathrm{CR}$ & 30 & 70 & - & 1.5 & $\mathrm{~A} 4$ \\
$100 \mathrm{M}$ & 30 & 70 & 5 & 1.0 & $\mathrm{~B} 1$ \\
$100 \mathrm{M}$ & 30 & 70 & - & 1.0 & $\mathrm{~B} 2$ \\
$100 \mathrm{M}$ & 30 & 70 & 5 & 1.5 & $\mathrm{~B} 3$ \\
$100 \mathrm{M}$ & 30 & 70 & - & 1.5 & $\mathrm{~B} 4$ \\
$4 \mathrm{CM}$ & 30 & 70 & 5 & 1.0 & $\mathrm{C} 1$ \\
$4 \mathrm{CM}$ & 30 & 70 & - & 1.0 & $\mathrm{C} 2$ \\
$4 \mathrm{CM}$ & 30 & 70 & 5 & 1.5 & $\mathrm{C} 3$ \\
$4 \mathrm{CM}$ & 30 & 70 & - & 1.5 & $\mathrm{C} 4$ \\
\hline
\end{tabular}


and needle, the solution was poured into a glass ring of $5.0-\mathrm{cm}$ diameter placed on the glass surface. The solvent was allowed to evaporate for $6 \mathrm{~h}$ in a thermostatically controlled oven at $60{ }^{\circ} \mathrm{C}$. The patches were stored in an airtight container under ambient conditions for 7 days prior to use.

\section{Evaluation of transdermal patches Physical appearance}

All the prepared patches were visually inspected for color, clarity, flexibility, and smoothness.

\section{Thickness of the patch}

The thickness of the drug loaded patches was measured by using a screw gage micrometer at three different points on the patches. Average values and standard deviation values of the three readings were calculated for each drug loaded patch.

\section{Uniformity of weight}

The patches were subjected to weight variation test by weighing all the patches on a digital weighing machine. The determinations were carried out in triplicate for each formulation. Average weight and standard deviation values were then calculated.

\section{Flatness study}

Flatness study was conducted to appraise that the prepared transdermal patches possess a smooth surface and shall not constrict with time. Three longitudinal strips were cut from the film at three different portions. The length of each strip was measured and the variation in length because of non-uniformity in flatness by determining percent constriction, with $0 \%$ constriction equivalent to $100 \%$ flatness. Percent constriction was obtained as $\left(l_{1}-l_{2}\right) / l_{1} \times 100$. Here, $l_{1}$ is the initial length of each strip, and $l_{2}$ is the final length of each strip.

\section{Folding endurance}

This test was carried out to check the efficiency of the plasticizer and the strength of the patch prepared using different polymers. The folding endurance is defined as the number of folds required to break any polymeric patch. The folding endurance was measured manually by repeatedly folding a small strip of the film $(2 \times 2 \mathrm{~cm})$ at the same place until it broke. The number of times the patch could be folded at the same place without breaking/cracking gave the value of folding endurance. Three patches of each type were taken for the test.

\section{Percentage moisture absorption/water vapor absorption}

The percent moisture absorption test was carried out to check the physical stability and integrity of the films in high humid conditions. The prepared films $\left(3.14 \mathrm{~cm}^{2}\right)$ were individually weighed accurately and exposed to $85 \pm 5 \%$ relative humidity in a desiccator containing $100 \mathrm{ml}$ of saturated solution of potassium chloride at room temperature. During this period, the films were weighed at regular time intervals of 24, 48, and $72 \mathrm{~h}$. The percent moisture absorption was determined from the following formula:

$$
\begin{aligned}
& \% \text { moisture uptake }=(\text { Final weight }- \text { Initial weight }) / \\
& \text { Initial weight } \times 100
\end{aligned}
$$

\section{Percentage moisture content}

This test was also carried to check the integrity of films under dry conditions. The individual transdermal films (of specified area) were kept in a desiccator containing fused anhydrous calcium chloride at room temperature. During this period, the films were weighed at regular time intervals of 24, 48, and $72 \mathrm{~h}$. The percentage moisture content was determined by using the following formula:

$$
\begin{aligned}
& \% \text { Moisture content }=(\text { Initial weight }- \text { Final weight }) / \\
& \text { Initial weight } \times 100
\end{aligned}
$$

\section{Water vapor transmission}

Water vapor transmission rate (WVTR) is defined as the quantity of moisture transmitted through unit area of film in unit time. Glass vials of equal volume and diameter were used as transmission cells. The cells were washed properly and dried in oven. Then, about $1 \mathrm{~g}$ of anhydrous fused calcium chloride was placed in each vial, and the patch was fixed over the brim of the vial with the help of an adhesive tape. These vials were then weighed and placed in desiccators containing saturated solution of potassium chloride to maintain $84 \%$ relative humidity. These cells were removed from the desiccators and weighed after 1st, 2nd, 3rd, 4th, 5th, 6th, and 7th day. The water vapor transmission rate was determined as follows:

$$
W . V . T .=W L / S
$$

Where $W$ is the weight of water vapors transmitted, $L$ is the thickness of patch and $S$ is the surface area exposed in square centimeter.

\section{Surface $\mathrm{pH}$}

Patches were kept in contact with $0.5 \mathrm{ml}$ of double distilled water for $1 \mathrm{~h}$ in glass tubes and were allowed to swell. A combined glass electrode was brought near the surface of patch and $\mathrm{pH}$ readings were taken after allowing an equilibration period of $1 \mathrm{~min}$.

\section{Drug content determination}

Pieces of $2 \times 2$ size were cut from each type of formulation and put in $100 \mathrm{ml}$ of phosphate buffered saline 
$\mathrm{pH} 7.4$ solution. The contents were magnetically stirred for $2 \mathrm{~h}$. The solution was then filtered through Whatman filter paper $(0.45 \mu)$ and diluted suitably with phosphate buffer saline $\mathrm{pH}$ 7.4. The solution was then analyzed for its absorbance at $289 \mathrm{~nm}$ using placebo patch as blank. From the absorbance values, the drug content was determined.

\section{In vitro drug release}

Franz diffusion cell was employed for the in vitro characterization of transdermal formulations. This is a reliable method for the prediction of drug transport across the skin from topical formulations. The receptor compartment of the diffusion cell was filled with $30.0 \mathrm{ml}$ of phosphate buffered saline ( $\mathrm{pH} 7.4$ ), and in vitro drug release studies were carried out using synthetic cellophane membrane. The prepared formulations were applied on to the membrane in the donor compartment and were uniformly spread onto the cellophane membrane. The assembly was constantly maintained at $37.0 \pm 2.0^{\circ} \mathrm{C}$ at $50 \mathrm{rpm}$. Samples (1.0 ml aliquots) were then withdrawn at suitable time intervals $(0,0.5,1,1.5,2,2.5,3,6,12$, and $24 \mathrm{~h})$ and replenished with an amount of medium to maintain the receptor phase volume to $30 \mathrm{ml}$. The samples were analyzed spectrophotometrically at $289 \mathrm{~nm}$.

\section{Drug permeation/ex vivo studies}

Drug permeation studies were carried out using the skin of male Wistar rats. The rats were sacrificed by spinal dislocation. The skin samples were cut, removed, and washed with normal saline. Adhering fat and connective tissue were removed using blunt-ended forceps. The skin was kept in normal saline solution for $6 \mathrm{~h}$. The hairs from the skin of the rat were shaved carefully to avoid peripheral damage. The receptor compartment of the Franz diffusion cell was filled with $30 \mathrm{ml}$ of phosphate buffered saline ( $\mathrm{pH}$ 7.4). The prepared formulations were applied over the skin of the rat in the donor compartment. The temperature of the assembly was constantly maintained at $37 \pm 2{ }^{\circ} \mathrm{C}$ and the stirring rate controlled at $50 \mathrm{rpm}$. Samples ( $5 \mathrm{ml}$ aliquots) were withdrawn at suitable time intervals $(0.5,1,2,3,4,6,8,10$, $12,14,16,18$ and $24 \mathrm{~h}$ ) and replaced with the same amount of medium to maintain the receptor phase volume to $30 \mathrm{ml}$. The samples were analyzed spectrophotometrically at $\lambda_{\max }$ of $289 \mathrm{~nm}$.

\section{Skin irritation studies}

Ethical clearance for the handling of experimental animals was obtained from the Institutional Animal Ethical Committee (IAEC), Panjab University, Chandigarh, and the studies were conducted as per approved protocol.

The albino Wistar rats were housed in cages, with free excess to standard laboratory diet and water. The dorsal abdominal skin of the rats was shaved carefully avoiding peripheral damage, before $24 \mathrm{~h}$ of conducting the study. Transdermal patch was applied onto the nude skin and covered with a non-sensitizing microporous tape. A $0.8 \% \mathrm{v} / \mathrm{v}$ aqueous solution of formalin was applied as standard skin irritant. The animals were applied with new patch each day up to 7 days. The formulation was removed after 7 days; score of erythema was recorded and was compared with standard. The score of erythema was read and recorded by the Draize scoring method (Draize et al. 1944) as score 0 for no erythema, score 1 for very slight erythema (light pink), score 2 for welldefined erythema (dark pink), score 3 for moderate to severe erythema (light red), and score 4 for severe erythema (dark red).

\section{Data analysis}

The raw data obtained from in vitro permeation studies was analyzed by applying factor for volume correction and drug losses during sampling using the following equation, which calculates the values of fraction of drug permeated and mean percent drug permeated along with standard deviation at varied times. $C_{\mathrm{c}}=C_{\mathrm{u}}+\left(\frac{V_{\mathrm{s}}}{V_{\mathrm{t}}}\right) \sum_{i=1}^{n-1} C_{\mathrm{i}}$

For the $n$th sample, $V_{\mathrm{s}}$ is the volume of sample withdrawn, $V_{\mathrm{t}}$ is the total volume of receptor medium, $C_{\mathrm{c}}$ is the corrected concentration, $C_{\mathrm{u}}$ is the uncorrected concentration of the $n$th sample, and $C_{\mathrm{i}}$ is the uncorrected concentration. Further, the corrected concentration was used to calculate the values of the amount of drug released and percent drug released at each time of sampling together with the rate of drug release.

Permeability coefficient is the velocity of the drug passage through the membrane/skin in $\mu \mathrm{g} / \mathrm{cm}^{2} / \mathrm{h}$. The permeability coefficient was calculated from the slope of the graph of percentage drug transported vs time as $P=$ slope $\times V_{\mathrm{d}} / S$

Here, $V_{\mathrm{d}}$ is the volume of the donor solution in milliliter, and $S$ is the surface area of tissue in square centimeter.

Flux ( $J$ value) is defined as the amount of material flowing through a unit cross-sectional barrier in unit time. It is calculated by:

$$
\begin{aligned}
\text { Flux }(J)= & \text { permeability coefficient } \\
& \times \text { conc. of donor solution }(\mathrm{mg} / \mathrm{ml})
\end{aligned}
$$

\section{Results and discussion}

\section{Physicochemical characterization of duloxetine hydrochloride}

The melting point of duloxetine hydrochloride was found to be in the range of 160 to $162{ }^{\circ} \mathrm{C}$ (melting point literature 163 to $167{ }^{\circ} \mathrm{C}$ ) (http://www.drugbank.ca/drugs/DB00476) 
and the octanol/water partition coefficient of duloxetine was found to be 3.84 (partition coefficient literature 4.0) (http://www.drugbank.ca/drugs/DB00476).

\section{Drug-polymer interaction studies}

The stability of a formulation amongst other factors depends on the compatibility of the drug with the excipients. Hence, any possible physical or chemical drugexcipient interactions were assessed by FTIR and DSC.

\section{Fourier-transform-infrared spectroscopy}

The FTIR spectra for the drug, polymers, physical mixtures of drug and polymer, and the transdermal formulations are displayed in Fig. 2. Salient spectral data for the drug and the polymers is as follows: duloxetine $\mathrm{HCl}$ : IR $\left(\mathrm{KBr}: \mathrm{v}, \mathrm{cm}^{-1}\right.$ ): 1579.05 (aromatic alkene), 1463.34 (thiophene ring), 1233.53 ( $\mathrm{C}-\mathrm{O}$ bond stretching).

Hydroxypropyl methylcellulose (HPMC): IR (KBr: v, $\mathrm{cm}^{-1}$ ): 3450.48 (O-H stretching), 2934.77 (C-H stretching, aliphatic), 1393.58 (C-O-C, stretching, dialkyl))

The characteristic absorption bands of the drug as well as polymers were found to be present at their usual positions in the formulations. This indicated the absence of any drug-polymer interaction in the formulation signifying their mutual compatibility.

\section{Differential scanning calorimetry}

The DSC thermograms for the pure drug and the formulation (drug + HPMC polymer) are shown in Fig. 3 . The DSC thermogram of PGB exhibited an endothermic peak at $173{ }^{\circ} \mathrm{C}$. In the DSC thermogram of the formulation, there was no appearance of any new peaks. Moreover, there was no change in peak shape and its onset. These results indicated that the chemical integrity of the drug was preserved and that there was no interaction between the drug and the polymer. A slight shift in the duloxetine $\mathrm{HCl}$ peak in the thermograms of drug loaded films could be attributed to the presence of moisture in the films. Thus, duloxetine $\mathrm{HCl}$ was found to be compatible with the HPMC polymer, suggesting that HPMC could be used for the preparation of the various transdermal patches.

\section{Evaluation of transdermal patches}

The prepared transdermal patches were evaluated to study the effect of different grades of HPMC polymer (with varied concentration), concentration of HPMC, and the presence of PEG 400 as plasticizer on the release kinetics of drug and on the physical characteristics of the film. These were evaluated for their physical appearance, weight uniformity, thickness uniformity, surface $\mathrm{pH}$, flatness test, water vapor absorption, water vapor transmission, drug content uniformity, in vitro drug release, ex vivo drug release across the rat skin, and skin irritation test. All the data sets were analyzed by paired $t$ test $(P<0.05)$.

\section{Physical parameters}

All the films were evaluated for their physical parameters (weight, thickness, folding endurance, diameter, area, flatness, and surface $\mathrm{pH}$ ), and they were found to be flexible, uniform, smooth, and transparent (Table 2). All the formulations were uniform in their weight, thickness, folding endurance, and diameter, with low SD values. The weight of the prepared transdermal patches for different type of formulations ranged between 160.7 $\pm 2.31 \mathrm{mg}$ and $245.9 \pm 2.45 \mathrm{mg}$, but within a formulation, all the patches showed low standard deviation values. The thickness of the patches varied from $0.047 \pm$ $0.0015 \mathrm{~mm}$ to $0.054 \pm 0.0017 \mathrm{~mm}$. Low standard deviation values in the film thickness measurements ensured uniformity of the patches which further indicated the reproducibility of the procedure followed for the preparation of the patches. Folding endurance values varied between $298.0 \pm 2.06$ and $308.6 \pm 2.08$. The flatness study showed that all the formulations had the same strip length before and after their cuts, indicating $100 \%$ flatness. Thus, no amount of constriction was observed which indicated that all patches had smooth flat surface which would be maintained when the patches are applied to the skin.

\section{Percent moisture absorption/water vapor absorption studies}

Percent moisture absorption studies were done to assess the integrity of films at high humid conditions. Water vapor absorption (moisture gained per $24 \mathrm{~h}$ ), expressed as number of grams of moisture absorbed per $24 \mathrm{~h}$ per square centimeter, was calculated as WVA rate $=W L / S$.

Here, $W$ represents the number of grams of water absorbed per $24 \mathrm{~h}, L$ is the thickness of the patch, and $S$ is the patch surface area in square centimeter. Percent moisture absorption was calculated as

$$
\begin{aligned}
& \text { Percent moisture absorption } \\
& \quad=\text { Final weight }- \text { Initial weight/Initial weight } \times 100
\end{aligned}
$$

The results are depicted in Table 3 and graphically shown in Fig. 4. The prepared patches showed minimal moisture absorption rates ranging from 0.0012 to $0.0055 \%$ thus ensuring general stability and protection from microbial contamination. There was a statistically significant difference $(P<0.05)$ between the patches formulated with polymer concentrations $1.0 \%$ and $1.5 \%$ respectively, as assessed by paired $t$ test, and increase in the HPMC concentration increased the moisture absorption capacity. The variation in polymer type (comparison of $\mathrm{A}, \mathrm{B}$, and $\mathrm{C}$ 


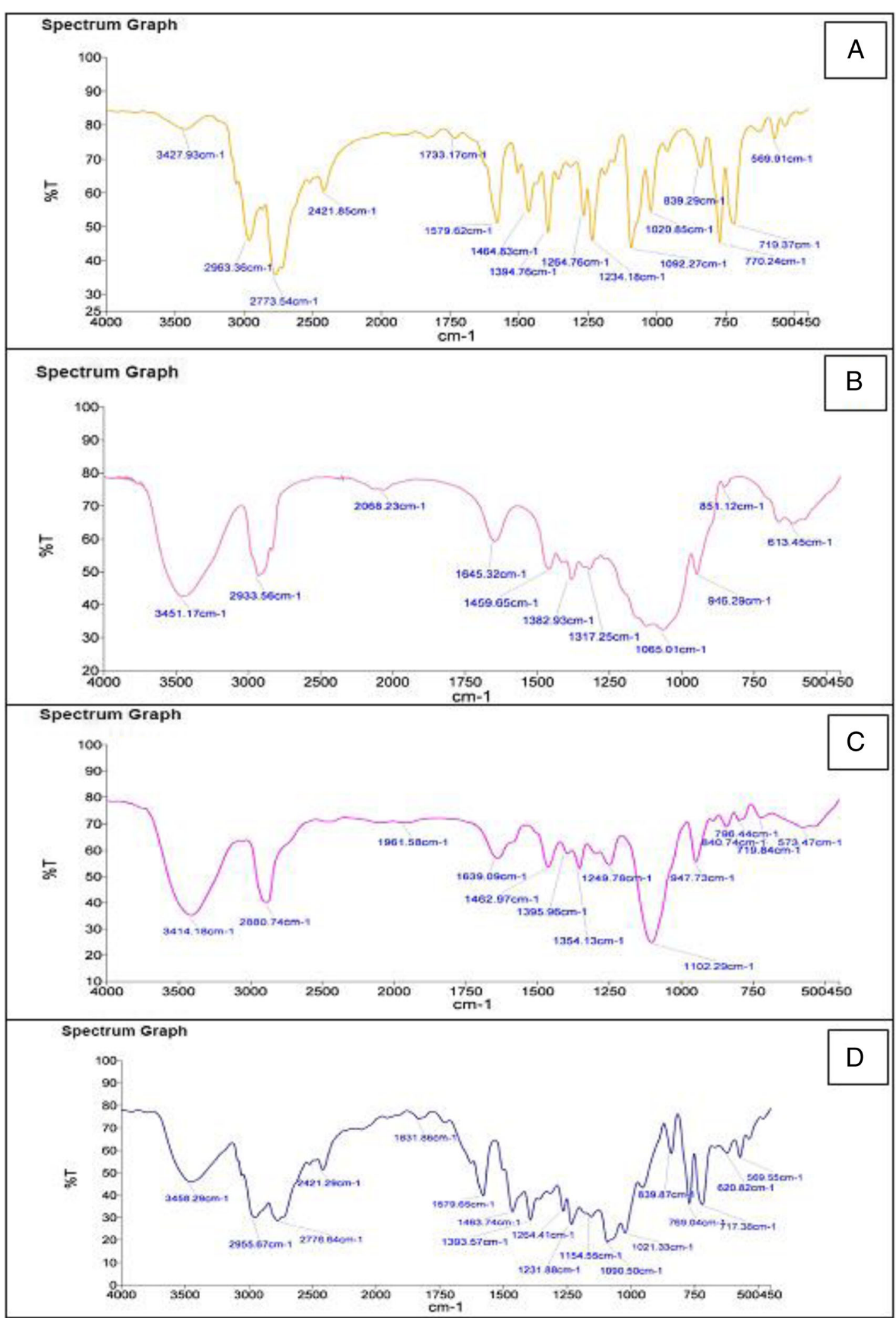

Fig. 2 FTIR spectra of duloxetine HCI (a); HPMC (K15 CR) (b); formulation with HPMC (K15 CR) (c); and physical mixture of DLX and HPMC (K15 CR) (d) 

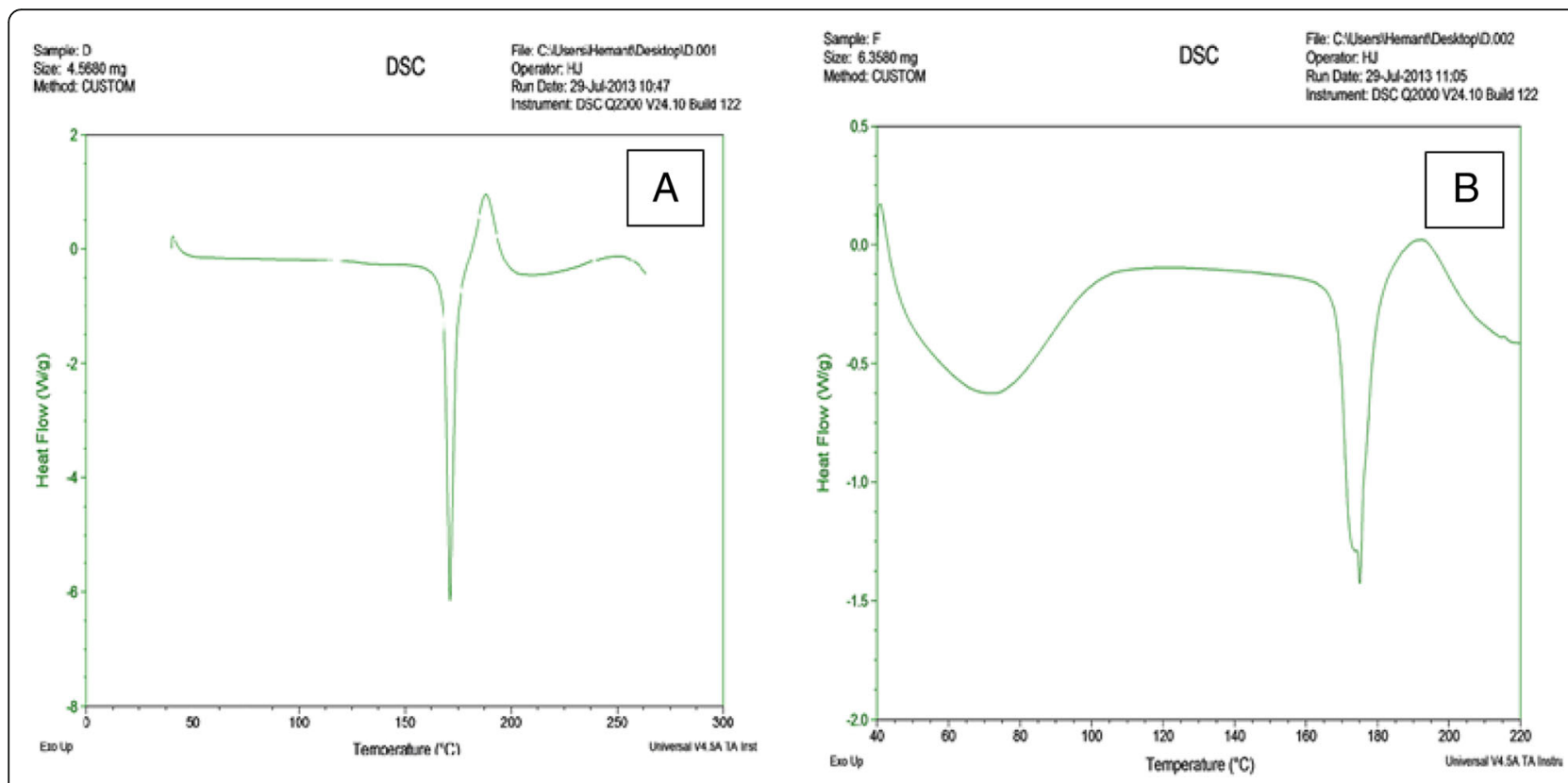

Fig. 3 DSC thermograms of duloxetine $\mathrm{HCl}(\mathbf{a})$ and the formulation (b)

series) or inclusion of the plasticizer PEG 400 did not significantly alter the moisture absorption rates.

\section{Moisture loss studies}

Moisture loss studies were carried out in order to determine the stability of the prepared patches under dry ambient conditions. The results obtained are given in Table 4. The percent moisture loss for the prepared transdermal patches was found to range from 1.84 to 7.34, reflecting a low moisture loss in all the prepared transdermal films with formulation B1 showing minimum loss and formulation $\mathrm{C} 4$ showing maximum moisture loss. The results for all the prepared transdermal patches reflected a low moisture loss for all the prepared transdermal films. Moisture loss was found to be significantly higher $(P<0.05)$ in patches formulated with K4CM (C series) compared with that in K100M (B series); however, the values for patches formulated with K15 M CR (B series) and K100M (C series) were found to be similar (assessed by paired $t$ test). The patches having lower concentration (1.0\%) of the polymer showed lower moisture loss compared to those with higher concentration (1.5\%). Further, the patches formulated with PEG 400 had significantly lower moisture loss indicating

Table 2 Physical characterization data for the transdermal patches

\begin{tabular}{|c|c|c|c|c|c|c|c|}
\hline $\begin{array}{l}\text { Formulation } \\
\text { code }\end{array}$ & $\begin{array}{l}\text { Weight }^{a} \\
(\mathrm{mg}) \pm S D\end{array}$ & $\begin{array}{l}\text { Thickness }^{a} \\
(\mathrm{~mm}) \pm S D\end{array}$ & $\begin{array}{c}\text { Folding }^{\mathrm{a}} \\
\text { endurance } \pm \mathrm{SD}\end{array}$ & $\begin{array}{l}\text { Diameter }^{\mathrm{a}} \\
(\mathrm{cm}) \pm \mathrm{SD}\end{array}$ & Area $\left(\mathrm{cm}^{2}\right)$ & Flatness (\%) & Surface $\mathrm{pH}$ \\
\hline $\mathrm{A} 1$ & $207.30 \pm 2.68$ & $0.053 \pm 0.001$ & $306.3 \pm 2.52$ & $4.03 \pm 0.03$ & 12.56 & 100 & 5.43 \\
\hline $\mathrm{A} 2$ & $168.10 \pm 3.64$ & $0.050 \pm 0.002$ & $302.0 \pm 1.73$ & $4.06 \pm 0.02$ & 12.87 & 100 & 5.48 \\
\hline A3 & $201.10 \pm 2.48$ & $0.048 \pm 0.001$ & $304.6 \pm 2.51$ & $4.10 \pm 0.05$ & 13.51 & 100 & 5.66 \\
\hline A4 & $160.70 \pm 2.32$ & $0.047 \pm 0.001$ & $300.0 \pm 1.73$ & $4.03 \pm 0.02$ & 12.87 & 100 & 5.56 \\
\hline B1 & $240.80 \pm 2.74$ & $0.054 \pm 0.001$ & $308.6 \pm 2.08$ & $4.06 \pm 0.02$ & 13.19 & 100 & 5.71 \\
\hline B2 & $184.00 \pm 2.16$ & $0.048 \pm 0.001$ & $308.0 \pm 2.64$ & $4.06 \pm 0.02$ & 12.87 & 100 & 5.74 \\
\hline B3 & $178.70 \pm 1.34$ & $0.050 \pm 0.002$ & $306.6 \pm 2.08$ & $4.08 \pm 0.02$ & 12.87 & 100 & 5.63 \\
\hline B4 & $161.80 \pm 2.21$ & $0.050 \pm 0.001$ & $303.3 \pm 1.53$ & $4.05 \pm 0.04$ & 12.87 & 100 & 5.67 \\
\hline C1 & $209.70 \pm 4.01$ & $0.049 \pm 0.001$ & $301.1 \pm 2.31$ & $4.11 \pm 0.02$ & 13.51 & 100 & 5.47 \\
\hline C2 & $203.70 \pm 3.77$ & $0.052 \pm 0.001$ & $298.0 \pm 2.64$ & $4.06 \pm 0.02$ & 13.19 & 100 & 5.47 \\
\hline C3 & $245.90 \pm 2.45$ & $0.053 \pm 0.002$ & $302.6 \pm 2.08$ & $4.06 \pm 0.02$ & 12.87 & 100 & 5.67 \\
\hline C4 & $207.10 \pm 2.77$ & $0.050 \pm 0.001$ & $298.3 \pm 2.08$ & $4.06 \pm 0.03$ & 13.19 & 100 & 5.52 \\
\hline
\end{tabular}

${ }^{a}$ Calculated as mean of measurements in triplicate 
Table 3 Data for water vapor absorption studies for the prepared transdermal systems

\begin{tabular}{|c|c|c|c|c|c|c|c|}
\hline \multirow{2}{*}{$\begin{array}{l}\text { Formulation } \\
\text { code }\end{array}$} & \multirow{2}{*}{$\begin{array}{l}\text { Average initial wt. } \\
\text { of patch* }(\mathrm{mg})\end{array}$} & \multicolumn{3}{|c|}{ Weight of patch (mg) } & \multirow{2}{*}{$\begin{array}{l}\text { Total moisture } \\
\text { gain }{ }^{a, *}(\mathrm{mg})\end{array}$} & \multirow{2}{*}{$\begin{array}{c}\% \text { moisture } \\
\text { absorption }^{b_{* *}}\end{array}$} & \multirow{2}{*}{$\begin{array}{c}\text { WVA rate } \\
\left(\mathrm{mg} \mathrm{cm} / \mathrm{cm}^{2} 24 \mathrm{~h}\right)^{c_{1}}\end{array}$} \\
\hline & & Day 1 & Day 2 & Day 3 & & & \\
\hline $\mathrm{A} 1$ & $210.43 \pm 2.10$ & 210.67 & 210.89 & 211.17 & $0.74 \pm 0.006$ & $0.3516 \pm 0.003$ & 0.003161 \\
\hline $\mathrm{A} 2$ & $167.12 \pm 1.12$ & 167.24 & 167.37 & 167.44 & $0.32 \pm 0.004$ & $0.1914 \pm 0.002$ & 0.001259 \\
\hline A3 & $198.33 \pm 1.72$ & 198.65 & 198.91 & 199.23 & $0.9 \pm 0.007$ & $0.4537 \pm 0.003$ & 0.003217 \\
\hline A4 & $159.7 \pm 1.23$ & 159.81 & 160.12 & 160.36 & $0.66 \pm 0.006$ & $0.4132 \pm 0.004$ & 0.002426 \\
\hline B1 & $243.11 \pm 2.17$ & 243.67 & 243.81 & 244.1 & $0.99 \pm 0.008$ & $0.4072 \pm 0.003$ & 0.004051 \\
\hline B2 & $182.49 \pm 1.81$ & 182.72 & 182.87 & 183.12 & $0.63 \pm 0.004$ & $0.3452 \pm 0.002$ & 0.002364 \\
\hline B3 & $177.53 \pm 1.59$ & 177.63 & 177.89 & 178.37 & $0.84 \pm 0.007$ & $0.4731 \pm 0.004$ & 0.003261 \\
\hline B4 & $161.17 \pm 1.51$ & 161.35 & 161.49 & 162.61 & $1.44 \pm 0.01$ & $0.8934 \pm 0.009$ & 0.005591 \\
\hline $\mathrm{C} 1$ & $211.26 \pm 2.01$ & 211.31 & 211.56 & 211.64 & $0.38 \pm 0.003$ & $0.1798 \pm 0.001$ & 0.001386 \\
\hline $\mathrm{C} 2$ & $206.55 \pm 2.09$ & 206.64 & 206.82 & 207.08 & $0.53 \pm 0.004$ & $0.2565 \pm 0.002$ & 0.002115 \\
\hline C3 & $245.19 \pm 2.13$ & 245.57 & 245.91 & 246.24 & $1.05 \pm 0.01$ & $0.4282 \pm 0.004$ & 0.004349 \\
\hline C4 & $207.31 \pm 2.10$ & 207.76 & 207.87 & 208.09 & $0.78 \pm 0.006$ & $0.3762 \pm 0.003$ & 0.002955 \\
\hline
\end{tabular}

*Measurements taken in triplicate

${ }^{a}$ Calculated as Final weight - Initial weight of the patch

${ }^{\mathrm{b}}$ Calculated as (Final weight - Initial weight/Final weight) $\times 100$

${ }^{c}$ Calculated as (Weight gained $(\mathrm{mg}) \times$ Thickness of patch $\left.(\mathrm{mm})\right) /$ Surface area of patch $\left(\mathrm{cm}^{2}\right)$

that the plasticizer will help the formulation remain stable and will also make it less brittle during long-term storage particularly under dry conditions.

\section{Water vapor transmission studies}

Water vapor transmission studies were carried out to determine the permeability characteristics of the transdermal patches. The water vapor transmission rate for the prepared patches ranged from 0.0009 to $0.0016 \mathrm{mg} \mathrm{cm} /$ $\mathrm{cm}^{2} 24 \mathrm{~h}$ (Table 5) indicating that all the formulations were permeable to water vapor. The low water vapor transmission (WVT) rates again emphasize the stability aspects on long-term storage. No statistically significant difference was seen with the change in type and concentration of the polymer. However, a statistically significant $(P<0.05)$ increase in water vapor transmission rate was seen in the presence of plasticizer PEG 400.

\section{Drug content}

Drug content analysis was performed for all the prepared transdermal systems by following standard method, and the results are displayed figuratively in Fig. 4. A near uniform drug content was noted for the prepared transdermal films ranging from 96.28 to 99.73\%. This suggests that the process employed to prepare the films was capable of affording uniform drug content and minimum variability.

\section{In vitro release studies}

The in vitro release profile is an important tool that predicts in advance how a drug will behave in vivo. Release studies are required for predicting the reproducibility of rate and duration of drug action. The in vitro drug release profiles of the formulations prepared from the three grades of HPMC, i.e., HPMC K15 M CR, HPMC $\mathrm{K} 100 \mathrm{M}$, and HPMC K4CM are included as Additional file 1: Table S1 and Figure S1.The cumulative percentage of the drug released in $24 \mathrm{~h}$ was found to be satisfactory for all types of transdermal films and drug release ranged from 80.77 (B3) to $95.59 \%$ (C1). The films returned very good permeability coefficient and flux values (especially $\mathrm{C} 1, \mathrm{C} 2$, and $\mathrm{A} 1$ ). The formulation with K100M (B series) displayed an overall lower drug release in $24 \mathrm{~h}$ compared to patches formulated with K15 M CR (A series) and K4CM, and this was statistically assessed by paired $t$ test. The slightly higher values seen for drug release in $\mathrm{C}$ series (in comparison to A series) could not be corroborated by $t$ test $(P<0.05)$. Pertinent enough to report is another fact that nearly $30 \%$ drug release (equivalent to one complete dose) was noted at 2 to $3 \mathrm{~h}$ with earliest first-dose release obtained with the patches $\mathrm{C} 1, \mathrm{~A} 1$, and $\mathrm{B} 1$ at $2 \mathrm{~h}, 3 \mathrm{~h}$, and $3 \mathrm{~h}$, respectively. A statistically significant difference was seen for varying concentration of the polymer (lower concentration leading to increased drug release) for all the three polymer series. Further presence of plasticizer (PEG 400) was seen to significantly improve the drug release profile.

A general comparison of results for all the formulated transdermal films suggests highest drug release for the patches $\mathrm{C} 1$ and $\mathrm{A} 1$ formulated with $\mathrm{K} 4 \mathrm{CM}$ and $\mathrm{K} 15 \mathrm{M}$ CR respectively (1.0\%) in the presence of plasticizer PEG 400 (5\% concentration). Further, these patches also afforded the best graded release of DLX with the first dose (30\%; $30 \mathrm{mg}$ DLX) (signifying the onset of therapeutic action) being released in $2 \mathrm{~h}$ and $3 \mathrm{~h}$ respectively and nearly complete drug release (equivalent to three doses, i.e., $60 \mathrm{mg}$ DLX) at $24 \mathrm{~h}$. 


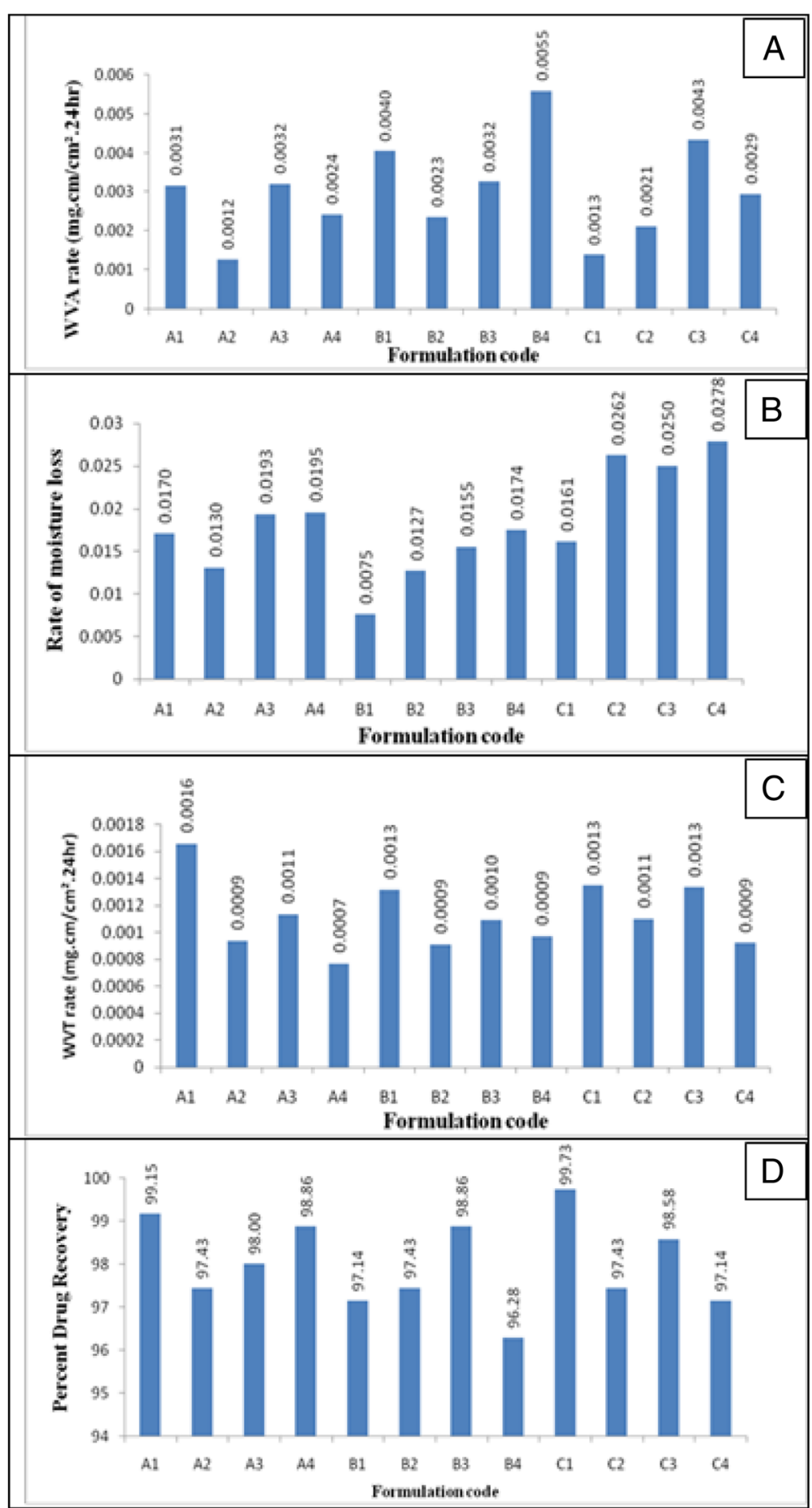

Fig. 4 Water vapor absorption studies (a), moisture loss studies (b), water vapor transmission studies (c), and drug content recovery studies (d) for the various formulations

\section{Ex vivo permeation}

The results for the ex vivo permeation for the transdermal patches prepared from the three grades of HPMC, i.e., HPMC K15 M CR, HPMC K100M, and
HPMC K4CM (Additional file 1: Table S2 and Figure S2) paralleled the results from in vitro release studies with the film $\mathrm{C} 1$ showing maximum ex vivo permeation of $81.63 \%$ and formulation B4 with minimum 
Table 4 Data for moisture loss studies for transdermal systems

\begin{tabular}{|c|c|c|c|c|c|c|c|}
\hline \multirow{2}{*}{$\begin{array}{l}\text { Formulation } \\
\text { code }\end{array}$} & \multirow{2}{*}{$\begin{array}{l}\text { Average initial patch } \\
\text { weight* }(\mathrm{mg})\end{array}$} & \multicolumn{3}{|c|}{ Weight of the patch $(\mathrm{mg})$} & \multirow{2}{*}{$\begin{array}{l}\text { Total moisture } \\
\operatorname{loss}^{\mathrm{a}}(\mathrm{mg})\end{array}$} & \multirow{2}{*}{$\begin{array}{l}\% \text { moisture } \\
\operatorname{loss}^{b, *}\end{array}$} & \multirow{2}{*}{$\begin{array}{l}\text { Rate of moisture loss }{ }^{c_{1, *}} \\
\left(\mathrm{mg} \mathrm{cm} / \mathrm{cm}^{2} 24 \mathrm{~h}\right)\end{array}$} \\
\hline & & Day 1 & Day 2 & Day 3 & & & \\
\hline A1 & $206.13 \pm 2.09$ & 204.98 & 203.11 & 202.14 & $3.99 \pm 0.042$ & $1.97 \pm 0.02$ & 0.0170 \\
\hline $\mathrm{A} 2$ & $165.06 \pm 1.60$ & 164.76 & 163.18 & 161.74 & $3.32 \pm 0.033$ & $2.05 \pm 0.023$ & 0.0130 \\
\hline A3 & $202.48 \pm 2.02$ & 200.38 & 199.10 & 197.06 & $5.42 \pm 0.051$ & $2.75 \pm 0.025$ & 0.0193 \\
\hline A4 & $159.18 \pm 1.39$ & 157.83 & 154.91 & 153.86 & $5.32 \pm 0.050$ & $3.45 \pm 0.031$ & 0.0195 \\
\hline B1 & $237.82 \pm 2.31$ & 236.77 & 236.22 & 235.98 & $1.84 \pm 0.012$ & $0.77 \pm 0.006$ & 0.0075 \\
\hline B2 & $183.23 \pm 1.79$ & 181.38 & 180.82 & 179.84 & $3.39 \pm 0.034$ & $1.88 \pm 0.014$ & 0.0127 \\
\hline B3 & $178.44 \pm 1.79$ & 177.76 & 175.51 & 174.44 & $4.00 \pm 0.043$ & $2.29 \pm 0.023$ & 0.0155 \\
\hline B4 & $159.61 \pm 1.49$ & 158.17 & 156.43 & 155.11 & $4.50 \pm 0.043$ & $2.90 \pm 0.027$ & 0.0174 \\
\hline C1 & $205.20 \pm 1.99$ & 203.41 & 202.11 & 200.78 & $4.42 \pm 0.044$ & $2.20 \pm 0.019$ & 0.0161 \\
\hline $\mathrm{C} 2$ & $199.45 \pm 1.89$ & 196.24 & 194.99 & 192.87 & $6.58 \pm 0.065$ & $3.41 \pm 0.028$ & 0.0262 \\
\hline C3 & $243.91 \pm 2.09$ & 241.79 & 238.12 & 237.87 & $6.04 \pm 0.060$ & $2.53 \pm 0.021$ & 0.0250 \\
\hline C4 & $209.88 \pm 1.99$ & 205.14 & 203.76 & 202.54 & $7.34 \pm 0.071$ & $3.62 \pm 0.031$ & 0.0278 \\
\hline
\end{tabular}

*Measurements taken in triplicate.

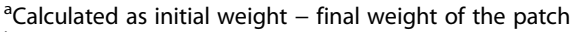

${ }^{b}$ Calculated as (initial weight - final weight/final weight) $\times 100$

${ }^{c}$ Calculated as (weight lost $(\mathrm{mg}) \times$ thickness of patch $(\mathrm{mm})$ )/surface area of patch $\left(\mathrm{cm}^{2}\right)$

permeation of $53.61 \%$. The values of the slope, permeability coefficient, and flux values for the various formulations are given in Table 6 for both in vitro and ex vivo studies. The drug permeation profiles were seen to be significantly different $(P>0.05)$ for all the three polymer types studied, i.e., K15 M CR, K100M, and K4CM as assessed by paired $t$ test. Further, the effect of factors like change in HPMC concentrations and presence of plasticizer on permeation results was found to be on the same lines as the in vitro release studies. As the HPMC concentration of the transdermal films is increased, the enhanced matrix system causes greater resistance to the drug release, resulting in the decreased drug release from the films. The percent drug release was significantly more $(P>0.05)$ in case of transdermal films having PEG 400 as plasticizer. The PEG 400 increases mechanical strength of the HPMC films but weakens the matrix structure against aqueous medium as it is a hydrophilic plasticizer. Due to this reason, the film-forming polymer was hydrated easily and swelled, leading to the fast release of the drug.

Table 5 Data for water vapor transmission studies on the formulated transdermal patches

\begin{tabular}{|c|c|c|c|c|c|c|c|c|c|c|}
\hline $\begin{array}{l}\text { Formulation } \\
\text { code }\end{array}$ & Initial wt. (g) & Day 1 & Day 2 & Day 3 & Day 4 & Day 5 & Day 6 & Day 7 & $\begin{array}{l}\text { Water vapor } \\
\text { transmitted }^{\mathrm{a}}(\mathrm{g})\end{array}$ & $\begin{array}{c}\text { WVT rate } \\
\left(\mathrm{mg} \mathrm{cm} / \mathrm{cm}^{2} 24 \mathrm{~h}\right)^{\mathrm{b}}\end{array}$ \\
\hline $\mathrm{A} 1$ & 51.81 & 52.03 & 52.16 & 52.25 & 52.38 & 52.55 & 52.83 & 52.99 & 1.18 & 0.0016 \\
\hline $\mathrm{A} 2$ & 51.26 & 51.38 & 51.48 & 51.57 & 51.69 & 51.76 & 51.89 & 51.97 & 0.71 & 0.0009 \\
\hline A3 & 51.54 & 51.66 & 51.78 & 51.91 & 52.08 & 52.23 & 52.32 & 52.45 & 0.91 & 0.0011 \\
\hline A4 & 51.34 & 51.43 & 51.48 & 51.57 & 51.68 & 51.76 & 51.85 & 51.97 & 0.63 & 0.0007 \\
\hline B1 & 51.7 & 51.86 & 52.04 & 52.17 & 52.29 & 52.44 & 52.51 & 52.64 & 0.94 & 0.0013 \\
\hline B2 & 51.56 & 51.62 & 51.71 & 51.8 & 51.91 & 52.01 & 52.18 & 52.29 & 0.73 & 0.0009 \\
\hline B3 & 51.45 & 51.58 & 51.73 & 51.86 & 52 & 52.07 & 52.19 & 52.29 & 0.84 & 0.0010 \\
\hline B4 & 51.31 & 51.36 & 51.48 & 51.67 & 51.8 & 51.89 & 51.97 & 52.06 & 0.75 & 0.0009 \\
\hline C1 & 51.82 & 51.98 & 52.15 & 52.29 & 52.49 & 52.51 & 52.69 & 52.88 & 1.06 & 0.0013 \\
\hline C2 & 51.77 & 51.88 & 52.01 & 52.14 & 52.29 & 52.41 & 52.48 & 52.57 & 0.8 & 0.0011 \\
\hline C3 & 51.57 & 51.69 & 51.87 & 52.04 & 52.17 & 52.34 & 52.44 & 52.54 & 0.97 & 0.0013 \\
\hline C4 & 51.75 & 51.83 & 51.94 & 52.07 & 52.19 & 52.29 & 52.38 & 52.46 & 0.71 & 0.0009 \\
\hline
\end{tabular}

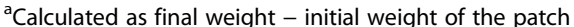

${ }^{\mathrm{b}}$ Calculated as (weight gained $(\mathrm{mg}) \times$ thickness of the patch $(\mathrm{mm}) /$ surface area of patch $\left(\mathrm{cm}^{2}\right)$ 
Table 6 Slope, permeability coefficient, and flux values for the formulations (in vitro and ex vivo studies)

\begin{tabular}{|c|c|c|c|c|c|c|}
\hline \multirow{2}{*}{$\begin{array}{l}\text { Formulation } \\
\text { code }\end{array}$} & \multicolumn{3}{|c|}{ In vitro studies } & \multicolumn{3}{|c|}{ Ex vivo studies } \\
\hline & Slope & $\begin{array}{c}\text { Permeability } \\
\text { coefficient }(\mathrm{cm} / \mathrm{h})\end{array}$ & Flux $\left(\mu \mathrm{g} / \mathrm{cm}^{2} / \mathrm{h}\right)$ & Slope & $\begin{array}{c}\text { Permeability } \\
\text { coefficient }(\mathrm{cm} / \mathrm{h})\end{array}$ & Flux $\left(\mu \mathrm{g} / \mathrm{cm}^{2} / \mathrm{h}\right)$ \\
\hline A1 & 0.554 & 0.0122 & 176.43 & 0.435 & 0.0095 & 138.53 \\
\hline $\mathrm{A} 2$ & 0.536 & 0.0118 & 170.70 & 0.39 & 0.0085 & 124.20 \\
\hline $\mathrm{A} 3$ & 0.536 & 0.0118 & 170.70 & 0.349 & 0.0076 & 111.14 \\
\hline A4 & 0.499 & 0.0109 & 158.91 & 0.316 & 0.0069 & 100.63 \\
\hline B1 & 0.557 & 0.0122 & 177.38 & 0.405 & 0.0089 & 128.98 \\
\hline B2 & 0.524 & 0.0115 & 166.87 & 0.377 & 0.0083 & 120.06 \\
\hline B3 & 0.476 & 0.0104 & 151.59 & 0.345 & 0.0075 & 109.87 \\
\hline B4 & 0.494 & 0.0108 & 157.32 & 0.321 & 0.0070 & 102.22 \\
\hline C1 & 0.549 & 0.0120 & 174.84 & 0.518 & 0.0114 & 164.96 \\
\hline C2 & 0.565 & 0.0124 & 179.93 & 0.493 & 0.0108 & 157.00 \\
\hline C3 & 0.524 & 0.0115 & 166.87 & 0.485 & 0.0106 & 154.45 \\
\hline C4 & 0.521 & 0.0114 & 165.92 & 0.437 & 0.0096 & 139.17 \\
\hline
\end{tabular}

\section{Hypersensitivity reactions}

TDDSs are intended for topical application, hence, the prime assurance needed for such formulations is their biocompatibility with the skin (site of action), i.e., their use must not lead to any kind of inflammatory reactions. To assess the potential of patches to cause skin irritation or sensitization, hypersensitivity tests were carried out on the rat's skin for the selected formulation. The animals were observed for 7 days for the development of signs of erythema (redness and flushing of skin) and edema (papules and wheals). The score of erythema was read and recorded by the Draize scoring method as score 0 for no erythema, score 1 for mild erythema (barely perceptible- light pink), score 2 for moderate erythema (dark pink) and edema, score 3 for moderate to severe erythema and moderate edema, and score 4 for severe erythema (extreme redness) and edema. None of the formulated transdermal patches were shown to demonstrate edema formation in comparison with the standard formalin group for 7 days. The patches A3, B1, and B3 showed very slight erythema reaction. This suggested the non-allergenic and non-irritant profile for the developed transdermal films.

\section{Conclusions}

Transdermal films of duloxetine hydrochloride have been successfully formulated as once daily formulation by solvent evaporation technique. Evaluation of the prepared films in terms of physical appearance, weight uniformity, thickness uniformity, surface $\mathrm{pH}$, flatness test, water vapor absorption, water vapor transmission, and drug content uniformity suggest that the method employed for formulation of the transdermal patches was reproducible and ensured excellent quality and uniformity in patch characteristics with minimum variability. Further, in vitro and ex vivo drug release studies for all the formulations showed that drug release equivalent to first dose of the drug was obtained in 2.0-3.0 h and nearly complete release (94\%) was achieved in $24 \mathrm{~h}$. These results show that transdermal delivery of duloxetine hydrochloride can have good potential applications in therapeutic arena offering advantages in terms of reduced dosing frequency, improved patient compliance, non-invasive characteristics, improved bioavailability, and easy termination of therapy. The required chronic administration of DLX should further accentuate the aforesaid advantages.

\section{Additional file}

Additional file 1: Table S1. In vitro drug release studies (Franz diffusion cell) with the transdermal patches. Table S2 Ex vivo drug release studies (Franz diffusion cell) with the transdermal patches. Figure S1 Percent in vitro release at various time intervals for formulations A1-A4, B1-B4, C1-C4. Figure S2 Percent ex vivo release at various time intervals for formulations A1-A4, B1-B4, C1-C4. (DOCX $281 \mathrm{~kb}$ )

\section{Acknowledgements}

Research grant provided by the University Grants Commission, New Delhi, India, is duly acknowledged. We sincerely thank Lupin Pharmaceuticals, Mumbai, India, and Hetero Labs, Baddi, India, for graciously providing us pure samples of duloxetine hydrochloride. We are also thankful to Panacea Biotech Limited, R\&D Centre, Lalru, Punjab, India, for generously providing us hydroxypropyl methylcellulose (HPMC) grades K15 M CR, K100M, and K4CM.

\section{Authors' contributions}

$\mathrm{AB}$ conceived this project, supervised this research work, and drafted the manuscript. AS performed the experimental work and carried out the data analysis. Both authors read and approved the final manuscript.

Competing interests

The authors declare that they have no competing interests. 


\section{Ethics approval}

Prior approval of the Institutional Animal Ethics Committee (IAEC, Panjab University, Chandigarh, India) was obtained for conducting the animal

studies, and all experiments were performed as per the approved protocol.

Received: 20 May 2015 Accepted: 12 November 2016

Published online: 28 November 2016

\section{References}

Ball S, Marangell LB, Lipsius S, Russell JM. Brain-derived neurotrophic factor in generalized anxiety disorder: results from a duloxetine clinical trial. Prog Neuro-Psychopharmacol Biol Psych. 2013;43(3):217-21.

Barry BW. Mode of action of penetration enhancers in human skin. J Control Release. 1987;6:85-97.

Barry BW. Novel mechanisms and devices to enable successful transdermal drug delivery. Eur J Pharm Sci. 2001;14:101-14.

Bennett R, Russell IJ, Choy E, Spaeth M, Mease P, Kajdasj D, Walker D, Wang F, Chappell A. Evaluation of patient-rated stiffness associated with fibromyalgia: a post-hoc analysis of 4 pooled, randomized clinical trials of duloxetine. Clin Ther. 2012;34(4):824-37.

Draize $\mathrm{JH}$, Woodard G, Calvery HO. Methods for the study of irritation and toxicity of substances applied to the skin and mucous membranes. J Pharmacol Exp Ther. 1944;82:377-90.

Freeman MP, Hirschberg AM, Wang B, Petrillo LF, Connors S, Regan S, Joffe H, Cohen LS. Duloxetine for major depressive disorder and daytime and night time hot flashes associated with the menopausal transition. Maturitas. 2013;75(2):170-4

Goldstein DJ, Lu Y, Detke MJ, Lee TC, lyengar S. Duloxetine vs. placebo in patients with painful diabetic neuropathy. Pain. 2005;116(1-2):109-18.

Gordon RA, Peterson TA. Four myths about transdermal drug delivery. Drug Deliv Tech. 2003;3:1-7.

Gupta JRD, Tripathi P, Irchhiaya R, Garud N, Dubey P, Patel JR. Skin permeation advancements. Int J Pharm Sci Drug Res. 2009;1:146-150.

Ilana L, Joseph K. Ultrasound and transdermal drug delivery. Drug Disc Today. 2004;9:670-6.

Izumoto T, Aioi A, Uenoyana S, Kariyama K, Azuma M. Relationship between the transference of drug from a transdermal patch and physicochemical properties. J Invest Dermatol. 1992;40:456-8.

Jain SK, Vyas SP. Magnetically responsive diclofenac sodium-loaded erythrocytes: preparation and in vitro characterization. J Microencap. 1994;11:141-51.

Leewen JHS, Lange RR, Jonasson AF, Chen WJ, Viktrup L. Efficacy and safety of duloxetine in elderly women with stress urinary incontinence or stresspredominant mixed urinary incontinence. Maturitas. 2008;60(2):138-47.

Mihaylova B, Pitman R, Tincello D, Vaart H, Tunn R, TimLin L, Quail D, Johns A, Sculpher M. Cost-effectiveness of duloxetine: the stress urinary incontinence treatment (SUIT) study. Value Health. 2010;13(5):565-72.

Prabhakar D, Sreekanth J, Jayaveera KN. Transdermal drug delivery patches: a review. J Drug Deliv Ther. 2013;3(4):213-21.

Prausnitz MR, Mitragotri S, Langer R. Current status and future potential of transdermal drug delivery. Nat Rev Drug Discov. 2004;3:115-24.

Rani S, Saroha K, Syan N. Transdermal patches a successful tool in transdermal drug delivery system: an overview. Der Pharmacia Sin. 2011;2(5):17-29.

Selvam RP, Singh AK, Sivakumar T. Transdermal drug delivery systems for antihypertensive drugs - A review. Int J Pharm Biomed Res. 2010;1(1):1-8,

Wells J. Preformulation preparations. In: Aulton WE, editor. Pharmaceutics: the science of dosage form design. 2nd ed. Edinburgh: Churchill Livingston; 2002. p. 341-66.

\section{Submit your manuscript to a SpringerOpen ${ }^{\circ}$ journal and benefit from:}

- Convenient online submission

- Rigorous peer review

Immediate publication on acceptance

- Open access: articles freely available online

- High visibility within the field

- Retaining the copyright to your article 